\title{
BAJOIT, GUY. LA TIRANÍA DEL GRAN ISA. CULTURA E REPRESENTAÇÕES SOCIAIS, 6: 9-24, MÉXICO, 2009. ${ }^{1}$
}

\author{
Resenhado por Cleide Emília Faye Pedrosa ${ }^{2}$
}

Guy Bajoit é doutor em Sociologia do Instituto de Ciências Políticas e Sociais da Universidade Católica de Lovaina, na Bélgica. Atualmente, é professor emérito da Unidade de Antropologia e Sociologia da Faculdade Aberta de Política Econômica e Social (FOBES), bem como do Instituto de Estudos do Desenvolvimento da Universidade Católica de Lovaina. O sociólogo tem uma vasta trajetória em universidades na Europa, como Espanha, Suíça e em algumas universidades latino-americanas. Suas obras abordam temáticas sobre mudanças sociais e culturais, sociologia do sujeito, identidades coletivas e individuais e, ultimamente, a socioanálise.

Quando situamos estudos transdisciplinares na área da linguagem, não podemos negar a grande contribuição que recebemos de áreas as mais diversas. Já há uma ou duas décadas, dialogamos com estudos culturais, sociológicos, comunicacionais para desenvolver pesquisas no campo da Linguística Aplicada, sobretudo, na linha das disciplinas de análise do discurso. Assim foi como entramos em contato com o sociólogo Guy Bajoit. Seus trabalhos saem do lugar comum defendido por uma sociologia mais tradicional. Pode-se afirmar que suas colocações sobre identidades e sujeitos marcam um lugar diferenciado, mesmo em meio as já tão ricas contribuições de

1. Disponível em :http://www.culturayrs.org.mx/revista/num6/ Bajoit.HTML, acessado em $31 \backslash 05 \backslash 2012$.

2. Professora Associada II na Universidade Federal do Rio Grande do Norte, mestrado e doutorado em Letras na UFPE, com pós-doutorado na UERJ. É líder do Grupo de Estudos do Texto e do Discurso (UFRN). Suas publicações contemplam a Análise Crítica do Discurso, bem como Educação a Distância, com abrangência nacional e internacional. 
outros autores sobre a temática, tais como Angers (2008), Hall (2006) e Bauman (2005).

Nesta resenha, o objeto de estudo será um modelo teórico apresentado pelo próprio Bajoit no artigo traduzido para o espanhol, "La tiranía del Gran ISA". ${ }^{3}$ Nele, o autor traça uma síntese de alguns de seus posicionamentos, sobretudo, com relação a identidades pessoais e os sujeitos. Na referida proposta, o autor defende que as mudanças pelas quais passam as sociedades contemporâneas originam-se no Individuo-Sujeito-Ator (ISA). Sugere o autor que essas mudanças não seriam "no sistema", mas "do sistema". A ascensão desse (espécie de deus) ISA - como principio abstrato - é o que seria responsável por essas mudanças. A tirania vem desse domínio do que ele chama, com um toque de ironia, de "O Grande ISA", ao refletir que saímos da tirania da razão para cair na tirania do Grande ISA, pois esse ISA busca, acima de tudo, a sua auto-realização, a busca de prazer imediato e a segurança frente às ameaças exteriores, além de impor esses mandamentos aos 'isas' concretos, individuais: "sê tu mesmo", "elege tua vida". Tais mandamentos geram tensões que afetariam as zonas de identidade do sujeito individual. Isso, se consideramos o momento cultural subjetivista ou identitário que vivemos.

Após este introito, Bajoit mapeia as três zonas identitárias do indivíduo: a identidade desejada (o que o individuo deseja ou busca fazer para se realizar pessoalmente); a identidade atribuída (o que o individuo faz para atingir o que ele considera como sendo expectativa dos outros para si a fim de conseguir reconhecimento social) e a identidade comprometida (o que ele faz para buscar a consonância existencial entre o desejado e o atribuído). Dentro de cada uma dessas esferas, desenvolvem-se zonas de tensões que resultam das relações socais do individuo na busca por constantemente construir sua identidade. Como essas esferas se recobrem parcialmente, as zonas de

3. Encontra-se também publicado em francês, "La Tyrannie du Grand ISA", como capítulo do livro organizado por Soulet M. H, La souffrance sociale. Nouveau malaise dans la civilization. Res Socialis 31, p.17-31, Fribourg: Fribourg Academic Press, 2007. 
tensões são sempre resultantes da aproximação ou afastamento entre essas esferas.

Como resultado desses movimentos de aproximações e afastamentos, gerando tensões identitárias, a estrutura da identidade individual se constrói em, pelo menos, sete zonas, uma central e seis periféricas que se localizam em esferas específicas ou no cruzamento entre elas:Z1, chamado de núcleo identitário por ser o ponto de encontro das três esferas identitárias (desejada, atribuída e comprometida); Z2, chamada de zona de realização desviante, porque o indivíduo busca sua realização pessoal em detrimento ao reconhecimento social; Z3, chamada de zona de submissão obrigada, pois o individuo age para atender ao reconhecimento social em perda de sua realização pessoal; Z4, nomeada de zona de autodestruição pessoal porque o individuo atua contra seus desejos e contra o reconhecimento social; $\mathrm{Z} 5$, apontada como zona de insubmissão, nela o individuo renuncia a ser ou fazer mesmo diante das expectativas alheias pois não responde a seus desejos; Z6, chamada de zona de repreensão porque o individuo renuncia seus desejos por proibição dos demais; Z7, nomeada de zona de inibição por ele não ter capacidade de ser ou fazer embora o deseje e \ou os outros também esperem que o seja ou faça.

Essas esferas formam a base para as tensões que o "Grand ISA" procura resolver a fim de atender seus mandamentos. Assim, dentro de um modelo cultural subjetivo: o indivíduo (menor) tem o direito-dever de auto-realização pessoal (ter um projeto), de se desenvolver e de se realizar, assim como de fazer o que gosta; o direito-dever de escolher livremente, de ser sujeito de sua própria existência (eleger o estilo de vida); o direito-dever ao prazer (buscar o prazer da vida), de desfrutar o direito a vida, sentir-se bem em seu coração, em seu corpo e em sua cabeça; o direito-dever de segurança (cuidar-se), de se proteger dos numerosos perigos e inseguranças que cercam a sociedade contemporânea. Estas são, para o autor, as novas "tábuas da lei", uma que esse modelo cultural e identitário penetra de maneira lenta, porém, seguramente em todos os campos relacionais de nossa vida cotidiana (família, escola, trabalho, política). 
Esse contexto descrito seria a base da (re \des)construção identitária do indivíduo, principalmente, ao valorizar a expansão de sua identidade desejada, o que acarretaria, obviamente, tensões com as outras esferas identitárias. Ao enfrentar o mal-estar gerado diante dessas tensões, o indivíduo, como sujeito na "gestão relacional de si”, constrói, sempre em um processo provisório, sua identidade individual (Bajoit 2008). Essas identidades individuais e fragmentadas se constroem através de diferentes tipos de sujeito. Reforçamos, aqui, que sujeito, no posicionamento de Bajoit (2012: 32): "é mais essa própria luta do que os frutos que ela traz".

Assim, se o indivíduo, na gestão relacional de si, constrói suas identidades nessas diversas esferas, sua construção enquanto sujeito e, consequentemente, como ator social, será diferentes diante de cada circunstância. Como sugere Bajoit (2012, p. 21): "Não é o sujeito, com efeito, que resolve o mal-estar identitário: essa solução diz respeito ao ator". Por exemplo, se o sujeito estiver manejando as tensões das Z2 e Z5, ele estará gerenciando estas tensões ao buscar fugir da marginalização; se o sujeito estiver trabalhando as tensões geradas entre Z3 e Z6, ele estará fugindo das tensões do conformismo; se o sujeito se vê incapacitado de trabalhar as tensões geradas nas Z4 e Z7, estamos diante de um sujeito anômico. Além desse quadro de sujeito, aqui mencionado, outros trabalhos do autor (Bajoit, 2006, 2008), apontam para os sujeitos que se manifestam em cada esfera identitária. Na esfera desejada: o altruísta, o estrategista, o autêntico; na atribuída: o conformista, o adaptador e o rebelde; na comprometida: o consequente, o pragmático e o inovador (PEDROSA 2012 a, b,c).

Essas contribuições do autor podem ser aproveitadas como uma efetiva aplicabilidade nos campo dos estudos linguístico-discursivos, sobretudo, na linha crítica que visa à busca de resultados para uma mudança social. 


\section{Referências bibliográficas}

ANGERS, Maurice. A sociologia e o conhecimento de si: uma outra maneira de nos conhecermos graças à sociologia. Instituto Piaget: Lisboa, 2008

BAJOIT, Guy. El cambio social, análisis sociológico del cambio social y cultural en las sociedades contemporáneas. Madrid: Siglo, [2003]2008.

. Tudo muda: proposta teórica e análise da mudança sociocultural nas sociedades ocidentais contemporâneas. Ed. Unijuí: RS, Brasil, 2006.

.Vers une théorie socio-analytique de la relation sociale. Texto inédito cedido pelo autor, 2012.

BAUMAN, Zygmunt. Identidade. Trad. Carlos Alberto Medeiros. Rio de Janeiro: Jorge Zahar Ed., 2005.

HALL, Stuart. A identidade cultural na pós-modernidade. $11^{\mathrm{a}}$. Edição. Trad. de Tomaz Tadeu da Silva e Guaraciara Lopes Louro. Rio de Janeiro: DP e A, 2006.

PEDROSA, Cleide Emília Faye. Abordagem sociológica e comunicacional do discurso (ASCD): uma corrente para fazer Análise Crítica do Discurso. Herança teórica da Sociologia (Aplicada) para a Mudança Social. 2012 a. Disponível em: http://www.ascd.com.br/, acessado em 02 de setembro de 2012, às 21:50

Abordagem sociológica e comunicacional do discurso (ASCD): contribuição aos estudos das identidades e dos sujeitos, $2012 \mathrm{~b}$.

Disponível em: http://www.ascd.com.br/, acessado em 02 de setembro de 2012, às 21:54.

- Abordagem sociológica e comunicacional do discurso: caminhos de análises no campo da Análise Crítica do Discurso, 2012.

Disponível em: http://www.ascd.com.br/, acessado em 02 de setembro de 2012, às 21:55. 


\section{Normas para publicação de trabalhos em Cadernos de Linguagem e Sociedade}

11. Os textos submetidos à publicação podem ser enviados por e-mail, no formato padrão Word for Windows, em fonte Times New Roman, tamanho 12, espaço 1,5 e conter até 20 laudas para artigos, ensaios e retrospectivas, sendo reduzidas para quatro laudas no caso de resenhas. A referida extensão inclui notas de rodapé (reduzidas ao mínimo) e referências bibliográficas. Se houver gráficos e anexos, o material todo não poderá ultrapassar as 20 laudas. As citações de mais de cinco linhas deverão aparecer em tamanho 11, destacadas do texto em recuo deslocado de $4 \mathrm{~cm}$ à esquerda. A linguagem dos trabalhos deve ser acessível, clara, evitando-se o estilo esotérico e o jargão incompreensível. Não serão aceitos trabalhos com indícios de linguagem sexista ou com qualquer tipo de expressão discriminatória baseada no preconceito.

12. L\&S incentiva colaboradores/as de todos os países a submeterem seus trabalhos de pesquisa inéditos, os quais serão avaliados anonimamente por dois membros do Conselho Consultivo e, em caso de discordância, por um terceiro parecerista ad hoc. Os trabalhos a serem enviados para publicação poderão ser escritos em português, inglês, espanhol ou francês, sob a forma de artigo, ensaio e/ou retrospectiva (estado da arte), bem como de resenha crítica. Artigos, ensaios e retrospectivas devem ser precedidos de Abstract (em inglês) e Resumo (em português), ambos elaborados em torno de 100 palavras, seguidos respectivamente de até 6 keywords/ palavras-chave.

13. Os trabalhos encaminhados a L\&S devem primar pela originalidade, razão pela qual não deverão ter sido submetidos à publicação em outro periódico nacional ou internacional, sendo concedidos a L\&S todos os direitos autorais referentes aos textos publicados.

14. Solicita-se aos autores um Curriculum Vitae resumido, em nota de rodapé (4 a 5 linhas), na primeira página do texto.

15. Os títulos e subtítulos devem ser claros e breves (aconselha-se levar ao título, no máximo, 11 palavras).

16. As tabelas e figuras deverão ser numeradas e receber títulos.

17. As referências citadas no texto devem ser apresentadas da seguinte forma: (Fairclough, 2000: 145) ou Fairclough (2000: 145). Use et al. quando citar obra de mais de dois autores ou autoras. As letras a, b, cetc. 
devem ser usadas no caso de serem citados trabalhos do/a mesmo/a autor/a publicados no mesmo ano. Todas as referências citadas no texto devem ser organizadas por ordem alfabética e apresentadas no final do trabalho, conforme as especificações em colchetes: [Livro]: Magalhães, I. $E u \quad e \quad t u$. A constituição do sujeito no discurso médico. Brasília: Thesaurus, 2000. [Artigo em coletânea]: Caldas-Coulthard, C. R. Man in the news. The misrepresentation of women in the news-asnarrative discourse.In: Mills, S. (Org.) Language and gender. Interdisciplinary perspectives. Harlow: Longman, 1995, p. 226-39. [Artigo em periódico]: Grigoletto, M. Funcionamento metafórico e construção de identidades no discurso colonial britânico. Cadernos de Linguagem e Sociedade, 4: 11-29, 2000.

18. Autores/as com titulação inferior à de Mestre só poderão publicar em co-autoria com professores/as doutores/as.

19. Os trabalhos deverão ser enviados por correio eletrônico para denizelena@gmail.com, em mensagem com o assunto "Submissão aos Cadernos de Linguagem e Sociedade". A mensagem do/a proponente deverá conter o(s) nome(s) completo(s) do(s)/da(s) autor(es)/autora(s), a afiliação institucional por extenso, bem como o endereço para contato. Deverão ser enviadas dois arquivos: o texto original completo e outro sem as pistas autorais, o que inclui a substituição dos nomes em eventuais citações a trabalhos anteriores dos/as autores/as pela palavra AUTOR/A, inclusive na lista de referências bibliográficas. Este arquivo anonimizado será encaminhado a pareceristas.

Guidelines for Contributors

1. The manuscripts should be submitted as e-mail attachments, saved in a standard Word for Windows format; withTimes New Roman, size 12, 1.5 space. The maximum length is 20 pages for articles, essays and retrospectives, and 4 pages for reviews, including essential footnotes and references. The language used in the paper should be accessible and clear. Esoteric style and jargon are to be avoided. Papers with sexist language or any kind of discrimination based on prejudice will not be accepted.

2. Papers will be evaluated anonymously by two members of the Advisory Board, and in case of disagreement a third ad hoc peer review will be provided. Papers should be written in Portuguese, English, Spanish or French, in the form of article, essay, retrospective (state of the art) or review. Articles, essays and retrospectives should be 
preceded by an Abstract (in English) and a Resumo (in Portuguese), both around 100 words and followed respectively by six keywords I palavras-chave.

3. Papers submitted to L\&S must be unpublished, which means that they should not have been submitted for publication elsewhere, nationally or internationally. Copyright of the papers will be transferred to $L \& S$.

4. Authors must provide a brief Curriculum Vitae, placed as a footnote (4 to 5 lines) in the first page of the paper.

5. Titles and subtitles should be clear and brief (not more than 11 words).

6. Quotations exceeding 40 words should be indented in the text. Tables and figures should be numbered, displaying titles. Text samples used as examples in analysis should be numbered.

7. References cited in the text should be presented in the following way: (Fairclough, 2000: 145) or Fairclough (2000: 145). Use et al., when citing more than two authors. The letters a, b, c, etc. should be used in case you cite papers/books by the same author that were published in the same year. All references cited in the text are to be organised in alphabetical order and presented at the end of the paper in this way: [book] Magalhães, I. $\mathrm{Eu}$ e tu. $A$ constituição do sujeito no discurso médico. Brasília: Thesaurus, 2000. [Chapter in a collection] Caldas-Coulthard, C. R. Man in the news. The misrepresentation of women in the news-asnarrative discourse. In: Mills, S. (Ed.) Language and gender. Interdisciplinary perspectives. Harlow: Longman, 1995, p. 226-39. [Paper in journal] Grigoletto, M. Funcionamento metafórico e construção de identidades no discurso colonial britânico. Cadernos de Linguagem e Sociedade, 4: 11-29, 2000.9.

8. Manuscripts should be emailed to denizelena@gmail.com. In the email, authors must inform their full name, institutional affiliation and postal address. Two files must be attached: one containing the full original text and another without the author details. The anonymization includes replacing the names of authors in any citations for the word AUTHOR, even in the list of references. This file will be subjected to anonymous referees. 